\title{
On being a physics major: student perceptions of physics difficulties, rewards, and motivations
}

\author{
Anne E. Leak \\ Department of Educator Preparation, Stout School of Education, \\ High Point University, One University Parkway, High Point, NC, 27268 \\ Krystina Williamson \\ Department of Physics, Barnard College, 3009 Broadway, New York, NY 10027 \\ Daryl L. Moore \\ Department of Leadership Studies, Stout School of Education, \\ High Point University, One University Parkway, High Point, NC, 27268 \\ Benjamin Zwickl \\ Department of Physics, School of Physics and Astronomy, \\ Rochester Institute of Technology, 84 Lomb Memorial Drive, Rochester, NY 14623
}

\begin{abstract}
Undergraduate majors' attitudes and perceptions about physics can strongly influence their development of a physics identity, persistence, and pursuit of physics-related careers. To explore students' attitudes and perceptions, we surveyed 178 physics majors nationally. To analyze this data, we used descriptive statistics and emergent methods of qualitative analysis. While data collection is ongoing, preliminary results show themes of physics majors' value for hard-work, broadly applicable problem-solving skills, and the rewarding quest for a meaningful application of their knowledge. Furthermore, we found that students position physics as a creative and communicative endeavor when provided with opportunities to do research and lab-work that values these aspects. This rich analysis of students' attitudes and perceptions about physics can help educators better align learning opportunities with students' needs and prepare students for a long-term and broadly applicable pursuit of physics.
\end{abstract}

2019 PERC Proceedings edited by Cao, Wolf, and Bennett; Peer-reviewed, doi.org/10.1119/perc.2019.pr.Leak Published by the American Association of Physics Teachers under a Creative Commons Attribution 4.0 license. Further distribution must maintain attribution to the article's authors, cover page, and DOI. 


\section{INTRODUCTION}

Physics as a field still struggles with undergraduate retention, especially for traditionally under-served student populations. One strategy that researchers have found to be successful in improving retention is by improving students' physics identity [1-3]. Carlone and Johnson (2007) developed a model for analyzing data with a science identity lens that views identity as a combination of self-recognition, social performance, and science competence [1]. Hazari and colleagues (2010) have built on Carlone's well-accepted identity model to further emphasize students' interest, students "desire/curiosity to think about and understand physics [3]." Their study found that teachers could improve students' physics identity by contextualizing physics in real-world applications and countering stereotypes about physics, especially as a single pursuit. Their research, and that of others, also highlights that physics identity development is more than a property of an individual student; rather it is relational, cultural, dynamic, and influenced by a range of factors [3, 4]. Part of a students' physics identity is based on how they (and others) see themselves as physicists, yet this involves not only their ideas about themselves, but their ideas about physics $[1,5]$. Furthermore, ideas about physics and the practices of physicists are strongly related to students' experiences within a physics community and the roles and practices they take up within that community [6].

How students see themselves with respect to physics, their physics identity, has implications for whether they will persist in physics and see physics as a viable career path [5]. Wang and Hazari (2018) identified the role of synergy between implicit (e.g., assigning the student a challenging task) and explicit (e.g., telling the student they should consider a physicsrelated career) teacher recognizing strategies in influencing students' identity [7]. This means that physics departments can recognize majors as physicists, or not, based on a variety of social interactions related to a [perceived] ability of the student with respect to a [perceived] nature of physics. Similarly, students can recognize themselves as aligned (or misaligned) with physics based on a [perceived] nature of physics.

In a longitudinal study of physics identity development, Irving and Sayre (2015) found that in students' early stages of their undergraduate physics major, many students do not yet see themselves as physicists because of their experiencebased perceptions of what it means to be a physicist. They also found that students' ideas of what it means to be a physicist are strongly tied to attainment of knowledge and participation in research $[4,6]$. A focus on the attainment of knowledge and participation in research has implications for students' identity, but also of the types of careers they associate as related to physics many of which do not necessary emphasize a quest for knowledge or solely involve research. Yet of the nearly 7,500 physics bachelor's degrees from 201314 who were surveyed a year after graduating by the American Institute of Physics (AIP), approximately $40 \%$ entered the workforce with half of these in the private sector $[8,9]$. In or- der for students to persist in physics and to prepare students for a broad range of careers, especially those in the private sector, students need a broad perception of what it means to do physics and be a physicist. Making physics more relevant to students' future careers will increase their marketability as well as add to the career-focus preparation that has been shown to improve retention [10].

In order to expand research on physics identity and career interests, we developed a survey as part of the NSF-funded PIPELINE network to explore, among others, the questions addressed in this paper: 1) What do students emphasize when asked to describe physics to a high school student considering majoring in physics and 2) How do students position physics with respect to other disciplines?

\section{METHODOLOGY}

To examine undergraduate physics majorsâ perspectives of physics and careers, we developed and distributed a survey nationwide. This research includes responses from 178 student participants from 12 colleges and universities in the Northeast, Midwest, South, and Southeast regions of the US. The PIPELINE survey is a fifteen to twenty minute long online survey that asks students to reflect on their education experiences, interest in physics, career options, and their perceptions of innovation and entrepreneurship aspects as part of physics. This study focuses on one particular open-ended free response question in the PIPELINE survey, which asks, "If you were to describe being a physics major to a senior in high school who was considering majoring in physics, what would you tell them about being a physics major to help them with their decision?" From this question the authors have used qualitative phenomenological coding methods to examine studentâs perceptions about physics as a discipline.

We used Qualtrics to administer the survey and NVIVO software to conduct and organize our coding. The first, second and third author individually conducted a first pass emergent open-ended coding of the responses using phenomenographic approaches $[6,11]$. Phenomenographic approaches take into account the limited number of ways in which something experienced (e.g., learning physics and being a physics major) can be understood. In this sense, student responses were analyzed to determine the most essential and distinctive aspects between the students and their experience [11]. Interrater agreement discussions were used to compare and merge perspectives of experienced phenomena from studentsâ responses into agreed upon themes. We then used matrix comparison coding tools in NVIVO to examine the overlap of themes between our open codes, which resulted in a codebook that included hierarchical and structural codes as well as thematic codes [12]. The data was then re-coded for the final set of 45 responses. Lastly, semantic coding was used to better identify and understand the nuanced relationships students perceived between physics other disciplines (math, engineering) and ideas (problem solving, theory, etc) [13]. This 


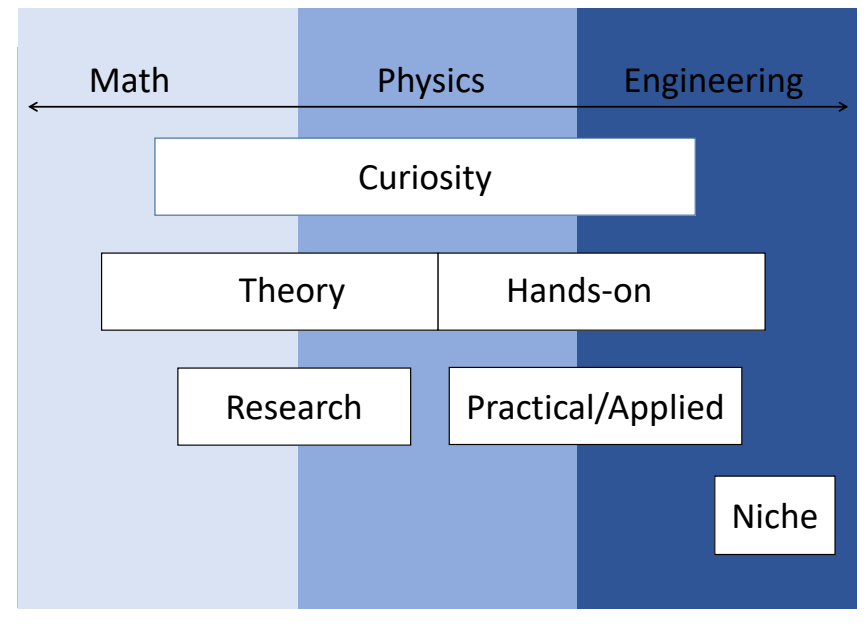

FIG. 1. Perceptions of Physics as Positioned with Math and Engineering.

analysis allowed for a deep investigation of a single guiding question in order to examine the complex perceptions students have about the nature of physics as a discipline.

\section{FINDINGS}

\section{A. Perceptions of Physics as Positioned with Other Disciplines}

The undergraduate physics majors surveyed often defined their discipline by positioning physics as similar or distinct from other disciplines, such as math and engineering. The lines drawn between engineering and physics and math and physics were often blurred, with attributes like curiosity applying to all three disciplines. Physics majors surveyed also compared physics to a more generalized "other majors" and "pre-college physics" to define their discipline. Figure 1 is a visual based on the ways students positioned these attributes with respect to math and engineering with respect to physics.

Physics vs. Engineering. Although students recognized the overlap between physics and engineering disciplines, they also noted practices and mindsets that they believed made the disciplines distinct. Both physics and engineering are perceived to have hands-on activities and practical/applied career options. Most often, physics was seen as being a necessary stepping stone to being a good engineer. The engineering discipline was made distinct from the physics discipline through the perception that engineers donât participate in research. As one student explained, "The main attraction [of physics] to this point for me has been a lot of very interesting research opportunities that I don't think a lot of engineering majors get." Another distinction was the versatility of physics problem solving compared to engineering. As one student put it, "A fairly common saying is engineers do one problem a thousand times, but physicists solve a thousand problems once."
Physics majors valued the diversity of problems they were taught to solve as providing flexibility on the types of problems and careers they applied their physics degree toward in the future.

Physics vs. Math. Students surveyed often noted the importance of math in doing and learning physics. In fact, being passionate in and knowledgeable of math was cited as being instrumental to the physics discipline. This passion and knowledge of math became increasingly important in theoretical physics, which was perceived as more abstract and mathheavy than other areas of physics. "If you love mathematics and you love the application of mathematics to real world phenomenon, physics is a great choice to major in." While students referenced the importance of math [and math interest] for doing physics, they also positioned physics related to math based on its stronger emphasis on theory. "Keep up with the higher level math courses, because having a good handle on the theory is essential." Some students see the theory as valuable, while others see physics as a more hands-on application of the math. Physics is not "just math," as many students noted, but an application of the math. Physics was also defined as different from math by noting that physics required an additional physical intuition/lens that the math discipline alone didn't have. As one student explained, "Physics is hard because it's mostly math hiding behind a mask." Students see physics as needing to do more skills using math tools, resources, or language. As one student describes, "Being a physics major is learning how to decipher complex situations written in the abstract laws of mathematics."

Physics vs. Pre-College Physics. In addition to comparing physics with other disciplines, physics majors noted that precollege physics experiences, including high school physics and pop culture physics, gave them a false expectation of what the physics discipline was. One student explains that, "There are so many more fields of physics than you learn about in high school, and being a physics major allows you to explore many of them." In another realization of physics being different from how it is portrayed on line, one student states that, "Real science is not like Youtube videos, there is infinitely more work behind the theorem than you would think." In answering a question about how physics majors would describe physics to a high school student, many responses related their perceptions in college back to their experiences and understanding of physics from when they were in high school.

Physics vs. Other Majors. Occasionally, students compared physics generally to "other majors," mostly noting the inflexibility and perceived ease of other disciplines. One student describes the uniqueness of physics by saying that, "Being a physics major involves developing a greater understanding of the world around us using the principles of mathematics. With this comes a training in creative problem solving skills, critical thinking, and an overall sense of intuition that other majors just don't foster as well." Another relates the general differences in studying physics to the effort students must put into studying. As they explain, "Majoring in Physics 
is a serious time commitment, that you must prepare for. Even other STEM majors won't understand the rigors of a physics major." Based on how they positioned physics with respect to other disciplines or themselves, students also provided valuable advice to future majors.

\section{B. How to Succeed as a Physics Major}

Along with giving their perspectives on the physics discipline, students also gave suggestions on how to be successful in the major. Figure 2 visually demonstrates what students perceived was necessary to be a successful physics major.

Attitudes and Mindsets. Physics majors highlighted four key attitudes and mindsets needed for success; curiosity, innovation, perseverance, and comfort with failure. Despite curiosity's importance, students found that some of their physics classes didn't allow them to be as curious as they had hoped. While one student noted that "Being a physics major is about having a natural curiosity about the world," while another explained that "being a physics major sometimes hinders my pursuit of curiosity of physics." Innovation was also an important attitude, especially in relation to lab design and problem solving. "Physics majors gain a certain intellectual capacity that allow us to be innovative." Students also emphasized that temporary failure and perseverance was a crucial component of being a physics major, typically said in opposition to the stereotypical view of physicists being innately intelligent. "I would say that they must work hard daily to succeed and always believe that they don't have to be intelligent to be physics majors. Failure is never a sign that they're incapable of being a physicist, it is actually their way to becoming a successful physicist."

Physics Community. Students emphasized the importance of their physics community in being successful. Students found that communication with their professors, even going so far as to sound like them was immensely helpful. "The longer you stay in the physics major the more you'll start to sound like the professors... if you just like imitating [the way they talk], it'll be much easier for you to stick through the 4 years." Furthermore, developing interpersonal skills was also important in retention and success in the major. "Communicating with peers and professors makes it [the physics major] a million times more bearable, so make sure to establish good relationships with those you will be working with."

Work Life Balance. Although students noted the role of maintaining work-life balance in being successful, the perception of what an appropriate work life balance differed. One student suggests that you [a high school student] must "Balance your life outside of physics. It is a demanding major and sometimes you can get a little lost in all the work, but it is important to maintain friendships." Another notes, "As physics majors, we sacrifice much of the social and extracurricular aspects of the college experience. Physics teaches you to prioritize in that way. The only physics majors I know who have survived the program did not feel as though they were

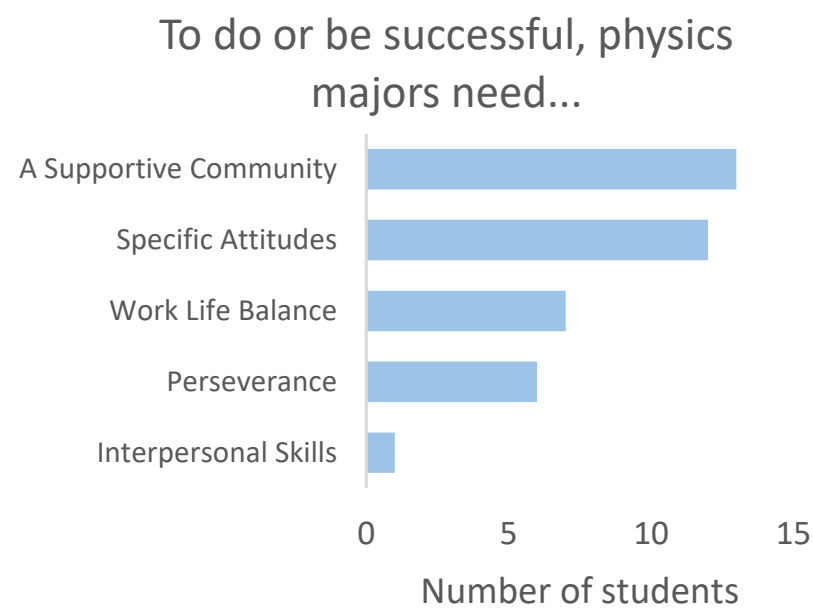

FIG. 2. Themes for responses describing how to do physics and succeed as a physics major.

missing out on anything." These two quotes demonstrate two extremes in a range of descriptions on the appropriate balance of physics and other aspects of life. Some students saw physics as a single pursuit, while others emphasized the need to pursue other interests in addition to physics.

\section{Rewards and Challenges of Being a Physics Major}

In describing physics to others, most physics majors described it as rewarding, but challenging. For example, one student describes physics as "challenging and timeconsuming, but the stuff you get to learn and do makes it worth it. Especially if you are truly passionate and engaged in learning physics." Over 150 students mentioned a reward of physics in some form, though there were a diverse range of reasons why they felt it was rewarding. For challenges, most students generalized these by describing physics as hard or by saying that to study physics they had to work hard. Where they did identify specific challenges, these often fell into categories of negative stereotypes and expectations, harsh grading policies, and an isolating culture. When describing rewards, physics majors often discussed them as reasons you [the hypothetical high school student they are addressing] should study it. The rewards physics majors identified are illustrated in Figure 3.

Learn how the universe works. The most common reward students referenced when explaining why you [a high school student] should study physics is learning how the universe works. Some students mentioned the world, some broadened this to the galaxy or universe, but the sentiment of exploring the unknown remained the same. One student describes this as learning "why the world works the way it does...You take something simple, like an apple falling, and then work to find out every last bit of information that can be found from that." 


\section{You should study physics because you...}

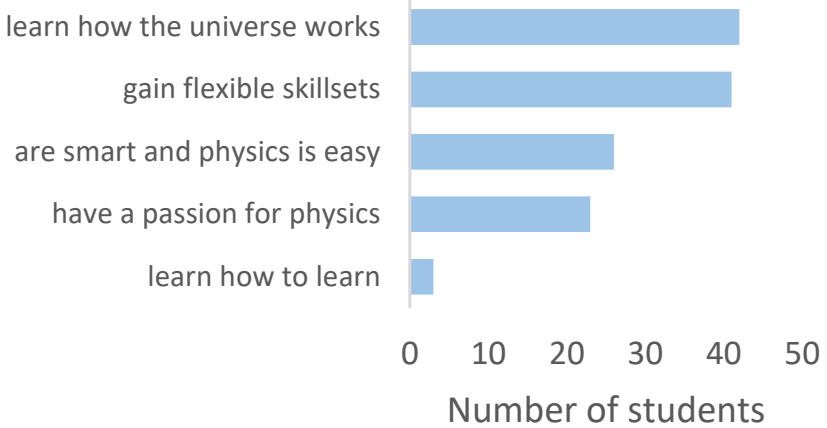

FIG. 3. Themes for responses related to the rewards of studying physics.

Others similarly described their passion for the unknown as a reason itself. As one student explains, "To be a physics major is to continually encounter new topics of interest and uncharted opportunities. Each day is full of spectacularly engaging puzzles requiring the marriage of critical thinking, intuition, and drive."

Gain flexible skillsets. In addition to a quest for universal understanding, many physics majors also saw the benefits of learning a flexible skill set. Students saw the advantages in the diversity of skills they learned as a physics major in order to prepare them for a variety of career paths. One student describes physics as open to possibilities by explaining, "It is as open as you want it to be. With physics you can focus in on whatever interests you, while still learning a wide breadth of information." Similarly, students reflected that physics majors learn more than content, rather they learn how to learn. For example, one student described being a physics major as "...learning how to learn and how to think differently about situations and challenges." In some instances, students specifically mentioned physics as teaching them not only to solve one type of problem, but any of the world's problems. They saw this as a way to innovate and have a range of possible careers they could pursue. One student describes what physics majors do by explaining that they "take real world situations and put them into the language of science so that they might solve problems or innovate." The idea of physics teaching problem solving and flexible ways to solve problems was present in at least 40 of their open ended responses describing physics to a future major.

Physics is easy. There is a strong perception by some physics majors surveyed that physics is easy and to study it, you need to be smart. When discussing this, they seemed to be warning high school students to do a self-assessment before committing to physics. For example, one student says, "I think that high schoolers should only pick hard physics if they are passionate and it comes easy to them at the high school level because it only gets harder." Even though some students found challenges to studying physics, the majority of those students also found that despite the challenges, the physics discipline offered them compelling enough rewards to stay. As one theory-loving student put it, "Being a physics major entails some negative stereotypes and a lot of hard work. But learning the laws and math is rewarding enough to stay."

\section{CONCLUSIONS}

When asked to describe physics to a high school student considering it as a major, students typically responded by positioning physics with respect to other disciplines (especially math or engineering) or their own high school experience, providing advice on how to succeed as a physics major, or discussing the rewards and challenges of learning physics. This study has implications for how students interpret physics with respect to their physics identity and potential for future careers. In fact, our findings support Irving and Sayre's results that many physics majors' perceptions of physics are strongly tied to attainment of knowledge, which could limit those who are motivated to study physics for other reasons [4]. Our results also touch on some of Hazari and colleagues findings that mathematics interests has a relationship with physics identity and that physics identity can be influenced by "making real-world connections, countering stereotypes that physics is a one-dimensional pursuit that requires giving up other desires [3]." Though our study did not track students and follow their retention, it is interesting to note that most students focused more on physics as a pursuit of knowledge than as a way to solve real-world problems. Also, physics majors' varied on how much they saw physics as a single pursuit or recognized the need for maintaining work-life balance. If instructors and departments address these perceptions of physics majors directly, they may be able to improve retention by changing students' assumptions about physics itself.

While our study includes 178 student participants from 12 schools in the US, it is limited by relying on one open-ended question. While we had multiple coders and applied a careful interpretation, future studies could include specific questions that delve into our initial findings more systematically and break out findings for subgroups based on demographic data. In addition to understanding the perceptions of physics majors, future research could also include faculty perspectives or explore changes in such perceptions, and student retention, longitudinally.

The way that physics majors perceive the physics discipline can have massive implications for who can access and participate in physics. This research aims to better identify majors' current perspectives of physics as a discipline, so that the physics community can consider the possibility of expanding the current definition of the physics discipline to improve majors' physics identity, further broaden participation within the discipline, and expand students' [perceived] access to a range of future careers. 


\section{ACKNOWLEDGMENTS}

We would like to thank the PIPELINE Network and the physics students who volunteered to participate in this study. This work is supported by the National Science Foundation's Improving Undergraduate STEM Education (IUSE) program under Award No. 1624882.

[1] H. B. Carlone and A. Johnson, Understanding the science experiences of successful women of color: Science identity as an analytic lens, Journal of Research in Science Teaching, 44(8), 1187-1218 (2007).

[2] H. Cheng, G. Potvin, R. Khatri, L. Kramer, R. M. Lock, and Z. Hazari, Examining physics identity development through two high school interventions, PERC 2018 Proceedings (2018).

[3] Z. Hazari, G. Sonnert, P. M. Sadler, M. Shanahan, Connecting high school physics experiences, outcome expectations, physics identity, and physics career choice: A gender study, Journal of Research in Science Teaching, 47(8), 978-1003 (2010).

[4] P. W. Irving and E. Sayre, Physics identity development: A snapshot of the stages of development of upper-level physics students, Journal of the Scholarship of Teaching and Learning, 13(4), 68-84 (2013).

[5] H. B. Carlone, C.M. Scott, and C. Lowder, "Becoming (less) scientific: A longitudinal study of students' identity work from elementary to middle school science" (2014).
[6] P. W. Irving and E. Sayre, Becoming a physicist: The roles of research, mindsets, and milestones in upper-division student perceptions, Physical Review Physics Education Research, 11, 020120 (2015).

[7] J. Wang, and Z. Hazari, "Promoting high school students' physics identity through explicit and implicit recognition (2018).

[8] P. Mulvey and J. Pold, Physics Bachelor's Initial Employment, Tech. Rep. (American Institute of Physics, 2015).

[9] S. Nicholson and P. Mulvey, "Roster of Physics Department with Enrollment and Degree Data," (2008).

[10] P. Heron and L. McNeil (Co-chairs), "Phys21:Preparing Physics Students for 21st-Century Careers," (American Physical Society, 2016).

[11] F. Marton, Phenomenography: A research approach to investigating different understandings of reality, Journal of Thought, 21(3), 28-49 (1986).

[12] J. Saldaña, The coding manual for qualitative researchers. Thousand Oaks, CA: Sage (2015).

[13] J.P. Spradley, J.P. Participant Observation. San Francisco: Holt, Rinehart and Winston (1980). 